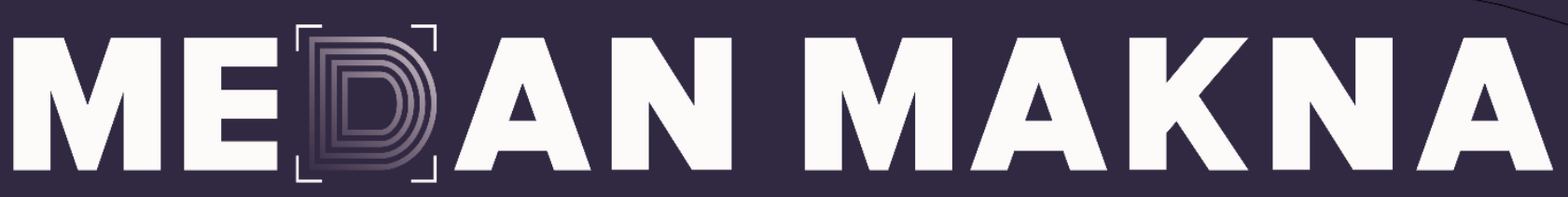

Jurnal IImu Kebahasaan dan Kesastraan

\title{
GAYA BAHASA SINDIRAN SEBAGAI BENTUK KOMUNIKASI TIDAK LANGSUNG DALAM BAHASA LAIYOLO
}

\section{Satire Language Style As A Form of Communication Indirect in the Laiyolo Language}

\author{
Nurlina Arisnawati \\ Balai Bahasa Sulawesi Selatan \\ Jalan Sultan Alauddin Km 7/Tala Salapang, Makassar \\ Pos-el: nhana.amran@gmail.com
} doi: $10.26499 / \mathrm{mm} . v 18 \mathrm{i} 2.2314$

\begin{abstract}
Abstrak
Penggunaan bahasa sindiran dalam kehidupan masyarakat Laiyolo cukup intens. Hal ini karena dilatarbelakangi oleh sifat masyarakat Laiyolo yang tidak suka berterus terang dengan berpegang teguh pada sikap tasipakaito 'saling memanusiakan' atau posianggarangi 'saling menghormati. Oleh karena itu, masyarakat Laiyolo menggunakan gaya bahasa sindiran sebagai bentuk komunikasi tak langsung mereka kepada orang yang telah melakukan sesuatu hal yang tidak menyenangkannya. Tulisan ini membahas tentang gaya bahasa sindiran sebagai bentuk komunikasi tidak langsung dalam bahasa Laiyolo. Tujuan Tulisan ini adalah mendeskripsikan penggunaan gaya bahasa sindiran sebagai bentuk komunikasi tidak langsung dalam bahasa Laiyolo. Metode yang digunakan adalah deskriptif kualitatif melalui teknik pengumpulan data pengamatan, simak-libat cakap, dan pencatatan. Hasil analisis data menunjukkan bahwa gaya bahasa sindiran sebagai bentuk komunikasi tidak langsung dalam bahasa Laiyolo dapat dilakukan dengan menggunakan tiga gaya bahasa sindiran, yaitu ironi, sinisme, dan sarkasme. Ketiga gaya bahasa sindiran ini pada dasarnya bertentangan dengan prinsip kerja sama dan prinsip sopan santun. Namun, ketiga gaya bahasa sindiran ini dianggap lebih aman dituturkan daripada mengkritik, menghina, mencaci, mengejek, dan sebagainya.
\end{abstract}

Kata-kata kunci: Gaya Bahasa Sindiran, Komunikasi Tidak Langsung, Bahasa Laiyolo

\begin{abstract}
The use of satire language in Laiyolo people's lives is quite intense. This is because it is motivated by the nature of the people of Laiyolo who do not like to be frank by sticking to the attitude of tasipakaito, 'humanizing each other' or posianggarangi 'mutual respect'. Therefore, Laiyolo people use satirical language as a form of indirect communication to people who have done something that is not pleasant. This paper discusses figure of speech of satire as a form of indirect communication in Laiyolo. The purpose of this paper is to describe the use of satirical as a form of indirect communication in Laiyolo. The method used is descriptive qualitative, the data collection technique through observational, conversation, and recording. The results of the data analysis show that satirical, namely irony, cynicism, and sarcasm. These three satirical are basically contrary to the principle of cooperation and the principle of politeness. However, these three satirical are considered safer spoken than criticizing, insulting, berating, mocking, and so on.
\end{abstract}

Keywords: Satirical, Indirect Communication, Laiyolo Language 


\section{PENDAHULUAN}

Manusia sebagai makhluk sosial memiliki saling ketergantungan dengan yang lainnya, baik secara ekonomis, psikis, intelektual ataupun sosial. Oleh karena itu, manusia memerlukan komunikasi satu sama lainnya agar bisa saling mengungkapkan gagasan, perasaan, maupun keinginannya yang tentunya melalui instrumen komunikasi yang dinamakan bahasa. Bahasa merupakan suatu cara komunikasi yang bisa memberikan pengaruh langsung bagi kedua belah pihak, penutur dan lawan tutur.

Bahasa sebagai alat komunikasi berfungsi menyampaikan pesan dari penutur (komunikator) kepada mitra tutur (komunikan). Akan tetapi, tidak semua dapat tersampaikan dengan baik. Kadang-kadang terjadi ketidaksepahaman atau perbedaan pendapat yang disebabkan oleh adanya "pemandegan" komunikasi. Komunikasi yang dibangun tidak efektif sehingga jauh dari hal saling memahami pesan yang ada. Bahkan, tidak jarang kita jumpai terjadinya konflik di mana-mana. Konflik yang terjadi itu, bahkan carut marut dalam bidang hukum, politik, dan lain-lain, serta banyaknya demonstrasi yang terjadi saat ini, merupakan wujud dari komunikasi yang tidak efektif (Pamungkas, 2012). Dalam situasi yang demikian, adakalanya manusia tidak saling memahami yang memicu terjadinya perdebatan atau perbedaan pendapat, perselisihan yang pada akhirnya melahirkan bahasa-bahasa yang berfungsi untuk menyindir satu sama lainnya. Padahal, manusia pada umumnya berinteraksi untuk membina kerja sama antarsesamanya $137 \mid$ dalam rangka membentuk, mengembangkan, dan mewariskan kebudayaannya dalam artian yang seluas-luasnya.

Sindiran yang ditandai dengan penggunaan kata-kata sindiran mempunyai kedudukan yang sangat sentral dalam aktivitas berkomunikasi secara verbal sebagai salah satu sarana untuk menjalankan fungsi emotif bahasa. Fungsi emotif bahasa yang dimaksud adalah fungsi untuk menyatakan perasaan yang dalam hal ini dilatarbelakangi oleh adanya rasa tidak suka atau tidak senang, jengkel, benci, dendam, dan sebagainya yang disampaikan melalui katakata sindiran. Sindiran adalah ujaran yang mengungkapkan kebalikan dari fakta yang sebenarnya yang biasanya digunakan untuk mencela orang secara implisit atau tidak langsung (Suprobo, 2015).

Berbicara tentang bahasa sindiran sebagai pemenuhan atas fungsi emotif bahasa, Jakobson (dalam (Wijana, I Dewa Putu, dan Rohmadi, 2006)) mengatakan bahwa fungsi emotif merupakan salah satu fungsi bahasa yang terpenting, di samping lima fungsi lainnya, seperti fungsi konatif, referensial, metalingual, poetik, dan fatis. Sementara Leech (dalam (Wijana, I Dewa Putu, dan Rohmadi, 2006)) mengungkapkan lima rumusan yang berbeda tentang fungsi bahasa, yaitu fungsi informasional, ekspresif, direktrif, estetik, dan fatis. Sindiran merupakan realisasi dari fungsi ekspresif.

Masyarakat Laiyolo pun mengenal bahasa sindiran. Bahkan frekuensi pemakaian bahasa sindiran ini pun cukup intens dalam 
kehidupan sehari-hari mereka. Hal ini karena dilatarbelakangi oleh sifat masyarakat Laiyolo yang tidak suka berterus terang dan berpegang teguh pada sikap tasipakaito 'saling memanusiakan' atau posianggarangi 'saling menghormati' dan sipohargai 'saling menghargai'. Oleh karena itu, masyarakat Laiyolo menggunakan bahasa sindiran sebagai bentuk komunikasi tak langsung mereka kepada orang yang telah melakukan sesuatu hal yang tidak menyenangkannya.

Masyarakat Laiyolo menggunakan bahasa sindiran untuk melepaskan rasa tidak puas dalam hati atau sesuatu yang tidak menyenangkan. Biasanya, bahasa sindiran ini digunakan untuk menyadarkan orang yang disindir atau setidak-tidaknya orang yang disindir mengetahui tentang perasaan atau suasana hati si penyindir agar tidak melakukan hal atau perbuatan yang serupa kepada si penyindir.

Belakangan ini, artikel atau penelitian yang mengkaji tentang sindiran telah banyak dikaji, di antaranya oleh (Wahyuni \& Kulup, 2013) yang berjudul Sindiran dalam Wayang Durangpo. Hasil penelitiannya menyimpulkan bahwa gaya bahasa sindiran dalam Wayang Durangpo merupakan bentuk kritik sosial yang terjadi di masyarakat dan sedang hangathangatnya dibicarakan. Sindiran dalam Wayang Durangpo berupa sindiran ironi, sinisme, dan sarkasme; (Purwati, Rosdiani, Lestari, \& Firmansyah, 2018) dengan judul Menganalisis Gaya Bahasa Metafora dalam Novel "Laskar Pelangi" Karya Andrea Hirata, yang 138 menyimpulkan bahwa gaya bahasa metafora dalam novel "Laskar Pelangi" mengungkapkan ungkapan secara tidak langsung berupa perbandingan analogis. Penelitian serupa juga dilakukan oleh (Solekhati, 2016) dengan judul Pemakaian Gaya Bahasa Sindiran pada Acara "Sentilan Sentilun" di Televisi, yang menyimpulkan bahwa: 1) jenis gaya bahasa sindiran pada acara "Sentilan Sentilun" di televisi ini terdapat 155 gaya bahasa sindiran yang dianalisis berdasakan jenis gaya bahasa satire, sarkasme, sinisme, ironi, dan inuendo; 2) makna gaya bahasa sindiran dikelompokkan menjadi jenis makna, dan sebab perubahan makna. Jenis makna pada gaya bahasa sindiran dibedakan menjadi dua yaitu makna primer dan sekunder. Selain itu, dalam penelitian ini ditemukan 91 sebab perubahan makna yang terdiri atas sebab perkembangan sosial budaya, perbedaan bidang pemakaian, asosiasi penyingkatan, pengembangan istilah dan proses gramatikal; dan 3) gaya bahasa sindiran pada acara "Sentilan Sentilun" dalam penelitian ini memiliki enam fungsi bahasa yang terdiri atas fungsi personal, instrumental, interpersonal, metalinguistik, referensial dan imajinatif. Fungsi bahasa yang mendominasi acara "Sentilan Sentilun" dalam penelitian ini adalah fungsi instrumental karena bahasa digunakan untuk menyampaikan gagasan, agar pendengar melakukan suatu kegiatan sesuai dengan keinginan penutur.

Penelitian yang memfokuskan pada bahasa Laiyolo, di antaranya: Konservasi Bahasa Daerah Laiyolo yang Hampir Punah di 
Kabupaten Kepulauan Selayar Sulawesi Selatan oleh (Muhsin, 2016). Penelitian ini mengungkapkan tentang konservasi bahasa Laiyolo agar tidak mengalami kepunahan. Penelitian bahasa Laiyolo lainnya, yaitu Antonimi Majemuk dalam Bahasa Laiyolo oleh (Rahmatiah, 2017), dan Deskripsi Morfem Pelaku dalam Bahasa Laiyolo oleh (Arisnawati, 2017). Kedua penelitian ini membahas aspek morfologi. Namun, penelitian tentang bahasa Laiyolo yang bersentuhan dengan aspek gaya bahasa dan teori pragmatik terutama prinsip kerja sama dan sopan santun masih sangat terbatas. Oleh karena itu, tulisan atau penelitian ini penting untuk dilakukan agar dapat mengetahui gaya bahasa sindiran sebagai bentuk komunikasi tidak langsung dalam bahasa Laiyolo. Selain itu, bahasa Laiyolo merupakan salah satu bahasa yang ada di Sulawesi Selatan yang terancam mengalami kepunahan karena jumlah penuturnya yang semakin berkurang.

Gaya bahasa sindiran yang dibahas dalam hal ini adalah jenis gaya bahasa berdasarkan teori Keraf yang dikaitkan dengan teori pragmatik, yaitu prinsip kerja sama dan prinsip sopan santun dengan mengetengahkan sebuah masalah, yaitu bagaimana penggunaan gaya bahasa sindiran sebagai bentuk komunikasi tidak langsung dalam bahasa Laiyolo? Tujuannya adalah untuk mendeskripsikan tentang penggunaan gaya bahasa sindiran sebagai bentuk komunikasi tidak langsung dalam bahasa Laiyolo. Selain untuk melengkapi penelitian yang ada, penelitian ini juga diharapkan dapat memberikan kontribusi di 139| bidang ilmu pengetahuan dengan menjadi bahan acuan atau alternatif materi dalam pengajaran di bidang linguistik, serta sebagai bentuk dokumentasi terhadap bahasa Laiyolo agar tidak mengalami kepunahan.

\section{LANDASAN TEORI}

Berbicara tentang sindiran, maka kerangka teori yang digunakan dalam tulisan ini akan bermula pada gaya bahasa karena bahasa sindiran merupakan bagian dari gaya bahasa.

Gaya bahasa dalam retorika dikenal dengan istilah style yang berasal dari kata Latin, stilus, yaitu semacam alat untuk menulis pada lempengan lilin dan pada perkembangannya, gaya bahasa atau style ini menjadi masalah atau bagian dari diksi atau pilihan kata yang mempersoalkan cocok tidaknya pemakaian kata, frasa atau klausa tertentu untuk menghadapi situasi tertentu (Keraf, 2009). Lebih lanjut dikatakan bahwa gaya bahasa memungkinkan kita dapat menilai pribadi, watak, dan kemampuan seseorang yang mempergunakan bahasa itu. Semakin baik gaya bahasanya, semakin baik pula penilaian orang terhadapnya; semakin buruk gaya bahasa seseorang, semakin buruk pula penilaian diberikan padanya. Oleh karena itu, gaya bahasa dapat dibatasi dengan cara mengungkapkan pikiran melalui bahasa secara khas yang memperlihatkan jiwa dan kepribadian penulis (pemakai bahasa). Gaya bahasa yang baik harus mengandung tiga unsur berikut, yaitu: kejujuran, sopan-santun, dan menarik (Keraf, 2009). 
Terkait dengan pernyataan tersebut, Dale et al (dalam (Tarigan, 2009)), mengungkapkan bahwa penggunaan gaya bahasa tertentu dapat mengubah serta menimbulkan konotasi tertentu. Sementara (Tarigan, 2009) menyatakan bahwa gaya bahasa dan kosakata mempunyai hubungan erat, hubungan timbal balik. Semakin kaya kosakata seseorang, semakin beragam pula gaya bahasa yang dipakainya. Peningkatan pemakaian gaya bahasa jelas memperkaya kosakata pemakainya. Salah satu gaya bahasa yang cukup intens pemakaiannya dalam kehidupan seharihari adalah sindiran.

Sindiran merupakan perkataan yang ditujukan untuk menyatakan sesuatu maksud kepada seseorang, tidak disebutkan atau dinyatakan secara tepat, tetapi hanya disampaikan secara sinis dengan dikias-kiaskan atau dilambangkan kepada perkara lain, sedangkan (Munsyi, 2011) mengatakan bahwa sindiran adalah perkataan untuk mengata, mengejek atau mencela seseorang (Munsyi, 2011). Tidak jauh berbeda dengan pernyataan tersebut, Merriam-Webster Dictionary dalam (Suprobo, 2015) menjelaskan bahwa sindiran 'tease' atau 'allusion' dan menyindir 'to tease' yaitu menertawakan atau mengkritik seseorang baik secara bersahabat atau bercanda maupun secara kasar. Sementara (Sugono, 2008) dalam Kamus Besar Bahasa Indonesia menjelaskan bahwa sindiran adalah perkataan (gambar dsb) yang bermaksud menyindir orang; celaan (ejekan dsb) yang tidak langsung.

Sindiran dikenal juga dengan istilah ironi, yaitu majas atau gaya bahasa yang 140 menyatakan makna bertentangan, dengan maksud berolok-olok. Maksud itu dapat dicapai dengan mengemukakan: 1) makna yang berlawanan dengan makna yang sebenarnya, 2) ketaksesuaian antara suasana yang diketengahkan dan kenyataan yang mendasarinya, dan 3) ketaksesuaian antara harapan dan kenyataan (Moeliono dalam (Tarigan, 2009)).

Sekaitan dengan hal di atas, (Keraf, 2009) mengelompokkan gaya bahasa sindiran dalam tiga bagian, yaitu: 1) ironi, adalah suatu acuan yang ingin mengatakan sesuatu dengan makna atau maksud berlainan dari apa yang terkandung dalam rangkaian kata-katanya; 2) sinisme, adalah suatu sindiran yang berbentuk kesangsian yang mengandung ejekan terhadap keikhlasan atau ketulusan hati; dan 3) sarkasme, adalah suatu acuan yang lebih kasar dari ironi dan sinisme. Ia adalah suatu acuan kepahitan dan celaan yang getir. Gaya ini selalu akan menyakiti hati dan kurang enak didengar. Sementara (Suprobo, 2015) mengatakan bahwa sindiran biasanya selain digunakan untuk mengejek lawan tuturnya, tetapi sindiran juga memiliki tujuan lain selain mengejek, yaitu untuk memprotes, untuk mengungkapkan ketidakpercayaan, mengekspresikan berbagai macam emosi seperti marah, sedih, kesal, keluhan, dan lain sebagainya.

Pengungkapan bahasa sindiran dalam masyarakat juga dapat dilihat dari situasi dan kondisi saat terjadinya komunikasi. Situasi dan kondisi yang dimaksud adalah latar belakang terjadinya komunikasi dan interaksi antarpemakai bahasa. Dalam kondisi tertentu, 
pemahaman bahasa tidak akan lengkap dan tepat jika konteks tuturan tidak dipahami, sehingga konteks tuturan berpengaruh besar dalam penentuan dan tujuan-tujuan berbahasa. Sementara dalam kajian pragmatik, terutama dalam retorika antarpribadi, prinsip ironi (sindiran) mengambil tempat di sisi prinsip kerja sama dan prinsip sopan santun (Tarigan, 2009). Dalam kajian pragmatik, prinsip itu disebut dengan maksim, yaitu pernyataan ringkas yang mengandung ajaran atau kebenaran.

Terkait dengan prinsip kerja sama, Gries (dalam (Chaer, 2010)) mengatakan bahwa setiap penutur harus menaati empat maksim kerja sama, yaitu 1) maksim kuantitas, yaitu maksim yang menghendaki setiap peserta tutur hanya memberikan kontribusi yang secukupnya saja atau sebanyak yang dibutuhkan oleh lawannya (tidak berlebihan); 2) maksim kualitas, yaitu maksim yang menghendaki agar peserta pertuturan itu mengatakan hal yang sebenarnya, hal yang sesuai dengan data dan fakta; 3) maksim relevansi, yaitu maksim yang mengharuskan setiap peserta pertuturan memberikan konstribusi yang relevan dengan masalah atau tajuk pertuturan; dan 4) maksim cara, yaitu maksim yang mengharuskan penutur dan lawan tutur berbicara secara langsung, tidak kabur, tidak ambigu, tidak berlebih-lebih dan runtut. Sedangkan terkait dengan prinsip sopan santun, Leech (dalam (Chaer, 2010)) mengatakan bahwa sebuah tuturan dianggap santun apabila memenuhi enam maksim kesopanan (kesantunan), yaitu 1) maksim kebijaksanaan, yaitu maksim yang 141 menggariskan bahwa setiap peserta pertuturan harus meminimalkan kerugian orang lain, atau memaksimalkan keuntungan bagi orang lain; 2) maksim penerimaan, menghendaki setiap peserta pertuturan untuk memaksimalkan kerugian bagi diri sendiri dan meminimalkan keuntungan diri sendiri; 3) maksim kemurahan, menuntut setiap peserta pertuturan untuk memaksimalkan rasa hormat kepada orang lain dan meminimalkan rasa tidak hormat kepada orang lain; 4) maksim kerendahan hati, menuntut setiap peserta pertuturan untuk memaksimalkan ketidakhormatan pada diri sendiri, dan meminimalkan rasa hormat pada diri sendiri; 5) maksim kecocokan, menghendaki agar setiap penutur dan lawan tutur memaksimalkan kesetujuan di antara mereka dan meminimalkan ketidaksetujuan di antara mereka; dan 6) maksim kesimpatian, mengharuskan semua peserta pertuturan untuk memaksimalkan rasa simpati, dan meminimalkan rasa antipasti kepada lawan tuturnya.

Prinsip ironi (sindiran) bersifat parasit terhadap keduanya. Dalam pengertian bahwa prinsip ironi (sindiran) merupakan suatu 'prinsip urutan kedua' yang memungkinkan seorang pembicara menjadi tidak sopan, tetapi kelihatan seolah-olah sopan; hal itu dapat terjadi dengan melanggar prinsip kerja sama secara luaran, tetapi pada akhirnya tidak mempertahankannya. Jika prinsip sopan santun memperkembangkan suatu prasangka terhadap rasa hormat lebih daripada konflik dalam hubungan-hubungan sosial, prinsip ironi (sindiran) memungkinkan kita menghindari kesopansantunan, 
mempromosikan penggunaan bahasa yang bersifat 'antisosial'. Hal tersebut pada akhirnya memunculkan pelanggaran terhadap maksim, terutama maksim kuantitas atau lebih sering lagi maksim kualitas.

Prinsip Iironi pada dasarnya mempunyai fungsi positif dalam mengizinkan agresi memanifestasikan dirinya dalam bentuk ucapan yang kurang berbahaya daripada kritik langsung, cacian, cercaan, ancaman, dan sebagainya. Cacian dapat secara mudah memancing cacian balasan, tetapi sindiran (ironi) tidak mudah menjawabnya dengan ucapan yang setimpal. Hal ini karena sindiran memiliki seni menyerang dengan kekuatan kata-kata dan disertai dengan sikap tidak bersalah sebagai bentuk pembelaan diri.

\section{METODE PENELITIAN}

Penelitian ini menggunakan metode deskriptif kualitatif untuk menggambarkan tentang bahasa sindiran sebagai bentuk komunikasi tidak langsung dalam bahasa Laiyolo.

Data dalam penelitian ini adalah bahasa sindiran dalam bahasa Laiyolo yang diperoleh melalui bahasa lisan yang dituturkan oleh penutur bahasa Laiyolo dan relevan dengan objek kajian dalam penelitian ini, yaitu tentang tuturan menyindir. Teknik pengumpulan data dilakukan dengan cara pengamatan, simak-libatcakap, dan pencatatan. Data yang telah dikumpulkan kemudian diseleksi dan diklasifikasikan menurut jenis atau tipe sindiran (ironi, sinisme, dan sarkasme). Data yang telah diseleksi dan diklasifikasikan tersebut kemudian dianalis berdasarkan teori tentang prinsip kerja sama dan prinsip kesantunan.

\section{PEMBAHASAN}

Menyindir atau sindiran merupakan tindakan mencela atau mengeritik secara tidak langsung atau tidak terus terang (KBBI, 2008, hlm. 1311). Selain digunakan untuk mencari kelemahan dan kekurangan seseorang atau sekelompok orang, sindiran dapat memperkuat posisi dan eksistensi atau keberadaan pihak yang memberikan sindiran. Dengan memberikan sindiran, seolah-olah pihak tersebut memiliki sikap, tindakan dan pandangan yang lebih baik daripada pihak yang mendapatkan sindiran. Sindiran dalam bahasa Laiyolo dikenal dengan istilah pseksindirik 'menyindir/sindiran'. Penggunaan sindiran dalam masyarakat Laiyolo bisa dikatakan cukup tinggi. Hal ini dilatarbelakangi oleh sikap masyarakat Laiyolo yang biasa mengucapkan kalimat secara basabasi atau tidak langsung kepada mitra tuturnya. Hal itu bertujuan menjaga perasaan mitra tutur agak tidak tersinggung dengan tuturan penutur. Dalam bahasa Laiyolo, ternyata bahasa sindiran ini bisa dikatakan cukup bertingkat karena dalam pengucapannya ternyata ada sindiran yang diucapkan dengan menggunakan kata-kata yang halus yang biasa dikenal dengan istilah ironi, ada sindiran yang berbentuk kesangsian yang mengandung ejekan atau dikenal dengan istilah sinisme, dan ada sindiran yang diucapkan dengan menggunakan kata-kata kasar yang dikenal dengan istilah sarkasme. Penggunaan ketiga 
tingkatan gaya bahasa sindiran tersebut dapat dilihat seperti berikut ini.

1) Ironi

Ironi adalah sejenis gaya bahasa yang mengimplikasikan sesuatu yang berbeda, bahkan ada kalanya bertentangan dengan apa yang sebenarnya dikatakan. Ironi dianggap sebagai sindiran yang lebih halus jika dibandingkan dengan sinisme dan sarkasme. Adapun contoh penggunaan bahasa sindiran dengan gaya bahasa Ironi ini adalah sebagai berikut.

(1) Kakika innya to menape puu helona, ka sangi lagirengea paranga ito.

'mengapa ada ya bagus sekali sifat, terus dia tengkari orang'

(Kok sifatnya bagus sekali ya, dia tengkari orang terus.)

(2) Addoh, ballona nilai laporokngu Nak, melek i lele.

'aduh bagusnya nilai rapormu Nak, rata-rata merah.

(Aduh, Nilai rapormu bagus Nak, ratarata merah)

(3) Sia ninro lambabo, gessingakda petokai doeknga.

'dia tidak boros, kuat cuma habisi uangnya.'

(Dia tidak boros, cuma kuat habisi uangnya.)

(4) Merajin puu dua koo, maong pinjengu ninro poli mubessuki

'rajin sekali kamu, biar piringmu tidak juga kamu bisa mencucinya.'

(Kamu rajin sekali, biar piring tidak bisa juga kamu cuci.)

(5) Ballo dua tulisengu, ninro sania labaca ito.

'bagus sekali tulisan kamu, tidak bisa baca orang.'

(Tulisanmu bagus sekali, orang tidak bisa membacanya.)
Contoh (1-5) merupakan contoh tuturan sindiran yang dituturkan secara tidak langsung dengan menggunakan gaya bahasa ironi. Pada tuturan (1), secara tidak langsung penutur menyindir mitra tuturnya dengan mengatakan sesuatu yang bertolak belakang dari hal yang sebenarnya, yaitu Kakika innya to menape puu helona, ka sangi lagirengea paranga ito 'Kok sifatnya bagus sekali ya, dia tengkari orang terus'. Padahal, dari tuturannya itu, penutur bermaksud menyindir mitra tuturnya sebagai orang yang memiliki sifat yang buruk karena suka bertengkar. Hal yang sama terjadi pada contoh tuturan (2) Addoh, ballona nilai laporokngu Nak, melek i lele. 'Aduh, Nilai rapormu bagus Nak, rata-rata merah'. Secara tidak langsung, penutur bermaksud menyindir mitra tuturnya yang tak lain adalah anaknya sebagai anak yang bodoh karena nilai rapornya buruk dengan rata-rata merah. Begitu pula dengan tuturan (3-4), yaitu Sia ninro lambabo, gessingakda petokai doeknga. 'Dia tidak boros, cuma kuat habisi uangnya' (3) dan Merajin puu dua koo, maong pinjengu ninro poli mubessuki 'Kamu rajin sekali, biar piringmu tidak bisa juga kamu cuci' (4). Kedua tuturan tersebut bermaksud menyindir mitra tuturnya yang dalam hal ini adalah adik penutur sendiri bahwa mitra tuturnya itu adalah orang yang boros karena tidak tahu menyimpan uang. Dengan perkataan lain bahwa mitra tuturnya itu suka berfoya-foya atau menghabis-habiskan uang (3), dan bermaksud menyindir mitra tuturnya sebagai pribadi yang pemalas (4). Sebagai seorang 
perempuan seharusnya terbiasa dengan pekerjaan rumah, termasuk mencuci piring. Akan tetapi, karena mitra tuturnya itu tergolong pemalas, cucian piring pun dibiarkan bertumpuk yang tentu saja menghasilkan pemandangan yang tidak menarik di dapur.

Pada tuturan (5), yaitu Ballo dua tulisengu, ninro sania labaca ito. 'Tulisanmu bagus, orang tidak bisa membacanya' penutur bermaksud menyindir mitra tuturnya yang memiliki tulisan yang jelek yang mengakibatkan orang lain sulit untuk membacanya.

Dengan mengungkapkan hal yang bertolak belakang dari fakta atau kenyataannya, tuturan (1-5) ini dianggap melanggar prinsip kerja sama, terutama maksim kualitas yang mengharuskan peserta pertuturan mengatakan hal yang sebenarnya dan juga melanggar prinsip sopan santun, terutama maksim kemurahan yang menuntut setiap peserta pertuturan untuk memaksimalkan rasa hormat kepada orang lain dan meminimalkan rasa tidak hormat kepada orang lain. Terlepas dari pelanggaran prinsip kerja sama dan prinsip sopan santun, tuturan ini dianggap jauh lebih baik dan lebih sopan daripada mengkritik, menghina, mencaci, mencerca, mengejek mitra tutur secara langsung. Alasan keduanya bahwa dengan bertutur secara bertolak belakang dengan fakta yang ada yaitu tidak langsung menohok mitra tutur sehingga tidak mudah bagi mitra tutur untuk membalas. Berbeda halnya jika penutur menyampaikan secara langsung berupa kritikan, hinaan, cercaan, ejekan, tentu mudah bagi mitra tutur memberikan serangan balik berupa pembalasan. 144
2) Sinisme

Sinisme adalah gaya bahasa yang berupa sindiran, berbentuk kesangsian dan mengandung ejekan terhadap keikhlasan dan ketulusan hati. Adapun contoh penggunaan bahasa sindiran dengan gaya bahasa sinisme ini adalah sebagai berikut.

(6) Poro pereha numbolombu dekdua kasangi pelonga akea sipo ri ito.

'barang murah juga ternyata selalu terus dipamer-pamer ke orang.'

(Ternyata barang murah juga selalu dipamer-pamer ke orang.)

(7) Kumengngeng dua kulongea, maong gaheeng melombu ninroda poli lagahea.

'capek saya lihatnya, biar pekerjaan mudah tidak juga bisa dikerjakan.'

(Saya capek melihatnya, Pekerjaan mudah pun tidak bisa dikerjakan.)

(8) Melombuda laka kaha itu jabatang, seppekiada komandang itu.

'mudah juga ternyata mendapatkannya jabatan, didekati saja bos/pimpinan.'

(Ternyata mudah mendapatkan jabatan, dekati saja bos/ pimpinan.)

(9) Pesaniku to ninro kedakko itona sabak lacerakdek poranga meruna kane lapeppau.

'Saya kira tidak pelit orangnya sebab pintar dan lembut kalau berbicara.'

(Saya kira orangnya tidak pelit sebab pintar dan lembut kalau berbicara.)

Contoh (6-9) merupakan contoh tuturan sindiran yang dituturkan secara tidak langsung dengan menggunakan gaya bahasa sinisme. Pada tuturan (6), secara tidak langsung, penutur menyindir mitra tuturnya dengan mengatakan sesuatu yang bertujuan mengejek seperti Poro 
pereha numbolombu dekdua kasangi pelonga akea sipo ri ito. 'ternyata barang murah juga selalu dipamer-pamer ke orang'. Tuturan tersebut disampaikan dengan nada sinis yang mengandung ejekan kepada mitra tutur. Dalam tuturan ini, secara tidak langsung, penutur bermaksud menyindir mitra tuturnya sebagai orang yang suka pamer dan mau dikata, sementara barang yang dipamerkan ternyata hanyalah barang murah, yang alih-alih semua orang bisa memilikinya. Sementara tuturan (7), Kumengngeng dua kulongea, maong gaheeng melombu ninroda poli lagahea, 'saya capek melihatnya, pekerjaan mudah pun tidak bisa dikerjakan'. Secara tidak langsung penutur menyindir mitra tuturnya dengan cara mengejek dan menyangsikan kemampuan mitra tuturnya dalam menyelesaikan pekerjaan yang cukup mudah dilakukan. Dalam hal ini, secara tidak langsung penutur menyindir mitra tuturnya sebagai pribadi yang malas, kurang cekatan, dan tidak mampu bekerja.

Pada tuturan (8) Melombuda laka kaha itu jabatang, seppekiada komandang itu 'ternyata mudah mendapatkan jabatan, dekati saja bos/pimpinan'. Secara tidak langsung penutur menyindir mitra tuturnya yang tak lain adalah rekan kerjanya sebagai orang yang mendapatkan jabatan melalui sistem pendekatan, tanpa melihat pengalaman dan prestasi kerja. Pada tuturan (9) Pesaniku to ninro kedakko itona sabak lacerakdek poranga meruna kane lapeppau, 'saya kira orangnya tidak pelit sebab pintar dan lembut kalau berbicara', secara tidak langsung dan dengan nada sinis, penutur 145 | menyindir mitra tuturnya sebagai orang yang pelit, dan sangat berbeda dengan dugaan si penutur selama ini tentang sikap mitra tutur yang dianggapnya sebagai orang yang pintar, lembut, dan penyayang. Orang yang memiliki sikap yang demikian, biasanya memiliki jiwa yang dermawan. Akan tetapi, fakta yang didapatkan penutur berbeda, mitra tuturnya yang tergolong pintar, lembut dan penyayang ternyata kurang dermawan.

Tuturan sindiran secara atau dengan gaya sinisme seperti pada tuturan (6-9) dianggap melanggar prinsip kerja sama, terutama maksim kualitas yang mengharuskan peserta pertuturan mengatakan hal yang sebenarnya; hal yang sesuai dengan data dan fakta dan maksim cara yang mengharuskan penutur dan mitra tutur berbicara secara langsung, tidak kabur, tidak ambigu, tidak berlebih-lebih dan runtut. Selain itu, tuturan (6-9) juga melanggar prinsip sopan santun, terutama maksim kemurahan yang menuntut setiap peserta pertuturan untuk memaksimalkan rasa hormat kepada orang lain dan meminimalkan rasa tidak hormat kepada orang lain dan juga maksim kerendahan hati yang menuntut setiap peserta pertuturan untuk memaksimalkan ketidakhormatan pada diri sendiri, dan meminimalkan rasa hormat pada diri sendiri serta maksim kesimpatian yang mengharuskan semua peserta pertuturan untuk memaksimalkan rasa simpati, dan meminimalkan rasa antipati kepada mitra tuturnya. Namun, terlepas dari pelanggaran prinsip kerja sama dan prinsip sopan santun, tuturan ini juga dianggap jauh lebih baik dan 
lebih sopan karena tidak menohok mitra tuturnya. Tuturan sindiran seperti tuturan (6-9) ini dianggap lebih aman untuk dituturkan daripada harus mengkritik, menghina, mencaci, mencerca, mengejek mitra tutur secara langsung.

Tuturan sindiran seperti tuturan (6-9) ini biasa dilakukan sebagai salah satu alternatif untuk menyerang mitra tutur dengan resiko yang sangat minim. Artinya, mitra tutur tidak mudah memberikan serangan balik berupa kemarahan, kebencian, ataupun memberikan sindiran balik itu sendiri karena sindiran seperti sinisme ini, tidak langsung tepat sasaran. Artinya, mitra tutur juga harus cerdas dalam mencerna dan memahami maksud perkataan si penutur. Selain itu, juga dibutuhkan kecerdasan dalam memilih dan menyusun kata jika ingin memberikan serangan sindiran balik. Sementara bagi penutur, setiap tuturan sindirannya itu tentu memiliki maksud, setidak-tidaknya menyadarkan mitra tuturnya tentang hal yang tidak berkenan dihatinya. Faktanya, kadang-kadang ada mitra tutur yang bersikap masa bodoh atau pura-pura tidak tahu dengan tujuan sengaja ingin membuat kesal si penutur atau memang mitra tuturnya yang kurang peka dengan situasi di sekelilingnya meskipun sudah disindir berkali-kali.

3) Sarkasme

Sarkasme merupakan suatu acuan yang lebih kasar dari ironi dan sinisme yang merupakan suatu acuan yang mengandung kepahitan dan celaan yang getir. Sarkasme dapat saja bersifat ironis, dapat juga tidak, tetapi yang jelas adalah bahwa gaya ini selalu akan menyakiti hati dan kurang enak didengar (Keraf, 146
2009:143-144). Adapun contoh penggunaan bahasa sindiran dengan gaya bahasa sarkasme ini misalnya sebagai berikut.

(10) Penassea kane mu peppau, nee mu sembau to mepepe.

'kasi jelas kalau bicara kamu, jangan kamu seperti orang bisu.'

(Perjelas kalau kamu bicara, kamu jangan seperti orang bisu.)

(11) Ritee mu taua matamu, sekeddippo mu linra aku.

'Di mana kamu simpan mata kamu, hampir saja kami kamu injak.'

(Di mana kamu simpan matamu, kamu hampir saja menginjak kami.)

(12)Sembau ko to dakang telingamu, ninro mina mu penrango apea nuripaukako. 'seperti kalau kamu tidak ada telingamu, tidak kamu dengarkan kalau ada diberitahukanmu.'

(kamu seperti tidak bertelinga, kamu tidak mendengarkan apa yang diberitahukan.)

(13) Merate dua bengkengu be, ninro mina mu taang ri sapo

'panjang juga kakimu ya, tidak pernah kamu tinggal di rumahmu.'

(Kakimu panjang juga ya, kamu tidak pernah tinggal di rumah.)

Contoh (10-13) merupakan contoh tuturan sindiran yang dituturkan secara tidak langsung dengan menggunakan gaya bahasa sarkasme. Pada tuturan (10), Penassea kane mu рерраи, пее ти sembau to mерере 'perjelas kalau kamu bicara, kamu jangan seperti orang bisu'. Secara tidak langsung, penutur menyindir mitra tuturnya seperti orang bisu, tidak jelas dan tidak dimengerti ketika berbicara. Meskipun terdengar kasar dan menyakitkan hati, tuturan ini 
tidak langsung menuding atau menghina mitra tuturnya sebagai orang bisu, tetapi seakan-akan melarang mitra tuturnya untuk bertutur atau berbicara seperti orang bisu. Oleh karena itu, tuturan sindiran seperti ini pun dianggap lebih sopan bila dibandingkan dengan menghina atau mengejek secara langsung mitra tuturnya sebagai orang bisu seperti: sembauko to mepepe kane peppau 'kamu seperti orang bisu kalau berbicara'. Hal yang sama juga terjadi pada tuturan (11) Ritee ти tаиа matamu, sekeddippo mu linra aku, 'di mana kamu simpan matamu, kamu hampir saja menginjak kami'. Secara tidak langsung penutur menyindir mitra tuturnya sebagai orang buta karena hampir menginjak si penutur. Tuturan ini pun dianggap lebih baik daripada harus bertutur secara langsung dengan mengejek atau menghina mitra tutur sebagai orang buta seperti mulinra aku hilo 'kau menginjakku buta'. Hal ini tentu akan lebih menyakitkan dan berpotensial untuk memunculkan serangan balik berupa kemarahan, kebencian yang ditandai dengan serangan ucapan atau kata-kata kasar yang mungkin lebih pahit daripada apa yang dituturkan oleh si penutur.

Pada tuturan (12) Sembau ko to dakang telingamu, ninro mina mu penrango apea nuripaukako, 'kamu seperti tidak bertelinga, kamu tidak mendengarkan apa yang diberitahukan' secara tidak langsung penutur menyindir mitra tuturnya tidak bertelinga karena tidak mau mendengarkan nasihat dan pada tuturan (13) Merate dua bengkengu be, ninro mina mu taang ri sapo, 'kakimu panjang juga ya, kamu tidak pernah tinggal di rumah'. Secara tidak langsung, penutur juga menyindir mitra tuturnya sebagai tukang jalan atau suka keluyuran. Tuturan ini pun dianggap lebih baik daripada harus bertutur secara langsung dengan mengejek atau menghina mitra tutur sebagai orang yang tidak bertelinga (12) dan sebagai tukang jalan atau suka keluyuran (13). Tuturan (12-13) ini tidak langsung menohok mitra tuturnya karena menggunakan kata perumpamaan, yaitu sembau 'sepertinya' (12) dan kalimat yang meminta persetujuan mitra tutur seperti Merate dua bengkengu be 'kakimu panjang juga ya' (13). Dengan demikian, tuturan (12-13) ini pun dianggap lebih sopan dan lebih aman digunakan daripada harus mencaci, mengejek, menghina, dan sebagaimya yang secara langsung dapat menyakiti hati mitra tutur. Meskipun tuturan ini dianggap melanggar prinsip kerja sama dan sopan santun.

\section{PENUTUP}

Bahasa sindiran merupakan salah satu media yang baik untuk dijadikan sebagai alat untuk menegur dan menasihati seseorang. Namun begitu, kita perlu peka dengan keadaan sekeliling sebelum menggunakannya. Hal ini karena sindiran yang diujarkan dalam keadaan tidak sadar akan menyebabkan suatu hubungan tidak harmonis. Bahasa sindiran sebagai bentuk komunikasi tidak langsung dalam bahasa Laiyolo dapat dilakukan dengan menggunakan tiga gaya bahasa sindiran, yaitu ironi, sinisme, dan sarkasme. Meskipun ketiga gaya bahasa sindiran tersebut melanggar prinsip kerja sama 
dan prinsip sopan santun, ketiga gaya bahasa sindiran tersebut dianggap sebagai media yang lebih baik dan lebih aman digunakan daripada mengkritik, menghina, mencaci, mengejek, dan sebagainya.

\section{DAFTAR PUSTAKA}

Arisnawati, N. (2017). Deskripsi morfem pelaku dalam bahasa laiyolo. 23(1), 139-150.

Chaer, A. (2010). Kesantunan Berbahasa. Jakarta: Rineka Cipta.

Keraf, G. (2009). Diksi dan Gaya Bahasa. Jakarta: PT Gramedia Pustaka Utama.

Muhsin, M. A. (2016). Konservasi Bahasa Daerah Laiyolo yang Hampir Punah di Kabupaten Selayar Sulawesi Selatan. Retrieved from http://www.ghbook.ir/ index. php? name

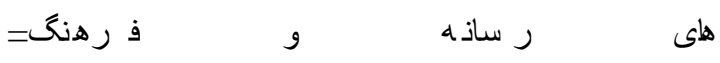
ذ وي ن ن و ن \&book_id=13650\&page $=73 \&$ chkhashk=ED9 C9491B4\&Itemid=218\&lang=fa\&tmpl=comp onent

Munsyi. (2011). Bahasa Sindiran. Retrieved from ww.adap.com.my/info.php?id=271

Pamungkas, S. (2012). Bahasa Indonesia dalam Berbagai Perspektif. Yogyakarta: Andi.

Purwati, Rosdiani, R., Lestari, R. D., \& Firmansyah, D. (2018). Menganalisis Gaya Bahasa
Metafora dalam Novel “Laskar Pelangi” Karya Andrea Hirata. Parole (Jurnal Pendidikan Bahasa Dan Sastra Indonesia), 1(3), 291-302. Rahmatiah, N. (2017). Antonimi Majemuk dalam Bahasa Laiyolo. SAWERIGADING, 23(2), 151. https:

//doi.org/10.26499/sawer.v23i2.255

Solekhati, N. F. (2016). Pemakaian gaya bahasa sindiran pada acara "sentilan sentilun " di televisi. Bahasa Dan Sastra Indonesia, 5(5), 113.

Sugono, D. (2008). Kamus Besar Bahasa Indonesia (keempat). Jakarta: PT Gramedia Pustaka Utama.

Suprobo, G. D. W. (2015). Sindiran dalam serial tv kath and kim ganggas dwi woro suprobo. Retrieved from http://etd. repository. ugm.ac.id/

Tariga, H. G. (2009). Pengajaran Pragmatik. Bandung: Angkasa.

Tarigan, H. G. (2009). Pengajaran Gaya Bahasa. Bandung: Angkasa.

Wahyuni, L. I. D., \& Kulup, L. I. (2013). Sindiran dalam Wayang Durangpo. Jurnal Buana Pendidikan, 9(16), 1-8.

Wijana, I.D.P., dan Rohmadi, M. (2006). Sosiolinguisti, Kajian Teori dan Analisis. Yogyakarta: Pustaka Pelajar. 